\title{
LOGÍSTICA REVERSA: COMO AS EMPRESAS COMUNICAM 0 DESCARTE DE BATERIAS E CELULARES?
}

\author{
REVERSE LOGISTICS: HOW DO COMPANIES REPORT THE DISPOSAL OF BATTERIES AND \\ CELL PHONES ? \\ LOGÍSTICA REVERSA: ¿CÓMO LAS EMPRESAS COMUNICAN EL DESCARTE DE BATERÍAS Y CELULARES?
}

\section{RESUMO}

A Lei 12.305 obriga as empresas fabricantes de celulares a estruturar programas de Logística Reversa e a comunicar seus clientes sobre como proceder após o término do ciclo de vida útil dos produtos. O objetivo desta pesquisa foi fazer um diagnóstico da comunicação de programas de Logística Reversa de empresas fabricantes de celulares no Brasil. Realizou-se uma pesquisa da perspectiva do consumidor, levantando as informações disponíveis em diversos canais de comunicação. O método abrangeu as técnicas de análise de conteúdo, entrevistas e levantamento. Os resultados evidenciam que as empresas investigadas não estão alinhadas com a legislação vigente. Nenhum dos programas estudados comunica adequadamente os consumidores de forma a estimular a sua participação no fluxo reverso dos produtos pós-consumo. Revelou-se também um descompasso entre intenção comportamental e comportamento dos consumidores potencializado pela deficiências de comunicação aqui identificadas.

PALAVRAS-Chave Comunicação, logística reversa, sustentabilidade, risco socioambiental, celulares.

Jacques Demajorovic jacquesd@fei.edu.br

Professor do Programa de Pós-graduação do Centro Universitário da FEI - São Paulo - SP, Brasil

Melby Karina Zuniga Huertas mhuertas@fei.edu.br

Professora do Programa de Pós-graduação do Centro Universitário da FEI - São Paulo - SP, Brasil

Juliana Alves Boueres juboueres@hotmail.com

Bacharel em Administração de Empresas pelo Centro Universitário da FEI - São Paulo - SP, Brasil

Adilson Gonçalves da Silva adilsons@glenmarkapharma.com

Bacharel em Administração de Empresas pelo Centro Universitário da FEI - São Paulo - SP, Brasil

Aloisio Sousa Sotano aloisio.sotano@ac1promo.com.br

Bacharel em Administração de Empresas pelo Centro Universitário da FEI - São Paulo - SP, Brasil

Abstract The Law 12305 requires cell phones manufacturers to organize Reverse Logistics programs and comunicatte customers on how to handle pos-consumption appliances. The objective of this research was to analyse, based on the principles of Integrated Marketing Communication, Reverse Logistics Programs communication at mobile phones manufacturers operating in Brazil. Therefore, a resesarch was conducted from a consumer perspective, focused on information available to consumers in different communication channels. Results show that the companies surveyed are not aligned with current legislation. None of the Reverse Logistics programs effectively communicate consumers in order to estimulate their participation in the reverse flow of post-consumption products. The research also revealed a mismatch between behavioral intention and behavior of consumers increased by the communication deficiencies identified here.

Keywords Communication, reverse logistic, sustainability, social environmental risk e cell phones.

Resumen La Ley 12.305 obliga a las empresas fabricantes de celulares a estructurar programas de Logística Reversa y a comunicar a sus clientes sobre cómo proceder después del término del ciclo de vida útil de los productos. El objetivo de este estudio fue hacer un diagnóstico de la comunicación de programas de Logística Reversa de empresas fabricantes de celulares en Brasil. Se realizó un estudio de la perspectiva del consumidor, haciendo un relevamiento de las informaciones disponibles en diversos canales de comunicación. El método abarcó las técnicas de análisis de contenido, entrevistas y relevamiento. Los resultados evidencian que las empresas investigadas no están alineadas con la legislación vigente. Ninguno de los programas estudiados comunica adecuadamente a los consumidores con el fin de estimular su participación en el flujo reverso de los productos pos-consumo. Reveló también una discrepancia entre intención comportamental y comportamiento de los consumidores, potencializada por la deficiencias de comunicación aquí identificadas. Palabras clave 


\section{INTRODUÇÃO}

A Logística Reversa (LR) ganha espaço cada vez maior no debate sobre gestão ambiental. Trata-se da responsabilização das empresas em relação aos produtos pós-consumo, assegurando que estes sejam recolhidos e encaminhados para reaproveitamento ou destinação segura. Entre os fatores que têm estimulado maior interesse pela LR, destaca-se o avanço da legislação em vários países, obrigando vários setores econômicos a responsabilizar-se pela gestão de seus resíduos. Porém, há também um movimento voluntário de empresas que adotam práticas de LR, ora estimuladas por suas políticas de responsabilidade socioambiental, ora por considerarem também as vantagens competitivas geradas nesse processo.

A implantação da LR, no entanto, precisa superar vários desafios, tais como o desenvolvimento de uma infraestrutura que possa assegurar o recolhimento dos resíduos pós-consumo e a identificação de alternativas para garantir o seu reaproveitamento ou destino seguro, minimizando impactos socioambientais. Além disso, muitas vezes, essa prática não é implementada pelo fato de as empresas considerarem sua operacionalização complexa e cara. Por fim, o estabelecimento de fluxos reversos depende, em grande medida, da coordenação dos diversos atores da cadeia produtiva que se disponham a colaborar no processo de retorno dos bens pós-consumo, sejam clientes, intermediários ou consumidores finais.

Informação voltada aos integrantes da cadeia produtiva, especialmente aos consumidores finais, é um dos elementos fundamentais de qualquer iniciativa na área de LR. É importante destacar que o papel da informação e da comunicação nos processos logísticos permaneceu historicamente em segundo plano na gestão da cadeia de suprimentos (BOWERSOX e CLOSS, 1996). A falta de tecnologias apropriadas contribuiu para que gestores desconsiderassem o papel da comunicação para aprimoramento do desempenho logístico. No entanto, o notável avanço, nas últimas décadas, dos sistemas de informação alterou essa percepção. Novos sistemas informatizados, mais eficazes e sistêmicos, fizeram da comunicação um elemento estratégico no debate atual sobre logística. A operação com estoques reduzidos ou o planejamento mais eficiente das atividades de transporte na cadeia são exemplos dessa nova fase. Bernon e Cullen (2007) mostram que as informações geradas via monitoramento de satélite permitem traçar rotas mais eficientes, evitando congestionamentos e re- duzindo tempo e consumo de combustível. Para eles, o contínuo desenvolvimento dos sistemas de comunicação informatizados oferece inúmeras oportunidades para a redução de custos e danos ambientais por meio dos processos de LR. Se essas contribuições dos sistemas de comunicação já são reconhecidas na literatura e nas práticas gerenciais, o papel da comunicação e da disponibilização de informação como indutor da participação dos consumidores na cadeia permanece em segundo plano. Para a implantação da LR de modo eficiente, ignorar esse aspecto representa um grande desafio, pois, muitas vezes, é o consumidor que inicia o fluxo reverso.

No Brasil, um dos principais setores envolvidos com a questão da LR é o da telefonia móvel. Desde junho de 2010, a Política Nacional de Resíduos Sólídos obriga os fabricantes de eletroeletrônicos, incluindo celulares, a implementarem programas de LR de aparelhos e baterias. Essa legislação federal obriga as empresas a gerar as informações sobre seus respectivos produtos que orientem os consumidores sobre riscos socioambientais, formas seguras de acondicionamento e caminhos para a devolução dos bens pós-consumo. Por outro lado, dados da Agência Nacional de Telecomunicações (ANATEL, 2010) mostram a rápida evolução do uso de aparelhos celulares no País, alcançando 185,1 milhões no primeiro semestre, conforme a Tabela 1.

Entretanto, a evolução do setor de telefonia móvel e o crescimento do consumo de celulares geram au-

\begin{tabular}{|c|c|c|}
\hline \multicolumn{3}{|c|}{$\begin{array}{c}\text { Tabela 1 } \\
\text { de teledensidade no Brasil }\end{array}$} \\
\hline Ano & Milhões de celulares & $\begin{array}{c}\text { Densidade/100 } \\
\text { habitantes }\end{array}$ \\
\hline 2002 & 1,7 & 20,3 \\
\hline 2003 & 43 & 26,2 \\
\hline 2004 & 65,6 & 36,6 \\
\hline 2005 & 86,2 & 46,6 \\
\hline 2006 & 99,9 & 53,2 \\
\hline 2007 & 120,9 & 63,6 \\
\hline 2008 & 150,6 & 78,1 \\
\hline 2009 & 173,9 & 90,5 \\
\hline 2010 & 185,1 & - \\
\hline
\end{tabular}

Nota: dado disponível apenas para o primeiro semestre de 2010 Fonte: Anatel, 2010. 
mento proporcional de descarte de aparelhos usados e baterias que contêm elementos nocivos ao meio ambiente. No caso das baterias, trata-se de resíduo classificado como perigoso pela Associação Brasileira de Normas Técnicas (ABNT), pois contém, em sua composição, substâncias tóxicas, como chumbo, cádmio e mercúrio, que podem contaminar o solo e a água (SOUZA; SANTOS; LIMA, 2007). A falta de tratamento ou a disposição final precária desses resíduos podem causar problemas envolvendo aspectos sanitários, ambientais e sociais, tais como a disseminação de doenças, a contaminação do solo e das águas subterrâneas e superficiais. Isso torna a LR um elemento-chave para a mitigação dos impactos socioambientais relacionados ao destino de apararelhos celulares e baterias. No entanto, a concretização de programas de LR enfrenta uma série de desafios, entre os quais se destaca a necessidade de empreender um esforço coordenado de atores, incluindo indústrias, distribuidores, governo e consumidores (ESPINOSA e TENÓRIO, 2005). Nesse contexto, o objetivo central deste trabalho foi fazer um diagnóstico da comunica- ção de programas de LR de empresas fabricantes de celulares atuando no Brasil.

\section{Logística Reversa: fatores motivadores e desafios}

Artigos abordando LR podem ser encontrados desde a década de 1970, porém foi apenas a partir de 1995 que ela se consolidou na produção acadêmica, surgindo os primeiros trabalhos focados na relação entre LR e questões socioambientais (RUBIO, CHAMORRO, MIRANDA, 2008).

Entre as várias definições de LR, uma das que têm sido mais utilizadas na literatura é a apresentada pelo Grupo de Trabalho Europeu em LR (RUBIO, CHAMORRO, MIRANDA, 2008, p. 1100), que a define como o "processo de planejar, implementar e controlar fluxos reversos de matéria-prima, em processos de estocagem, embalagem e produtos finais, das fases de produção, distribuição e consumo para sua recuperação ou disposição apropriada". Assim, a LR implica que o enfoque restrito de encontrar as alternativas mais eficientes para

\section{Figura 1 - Esquematização da LR}

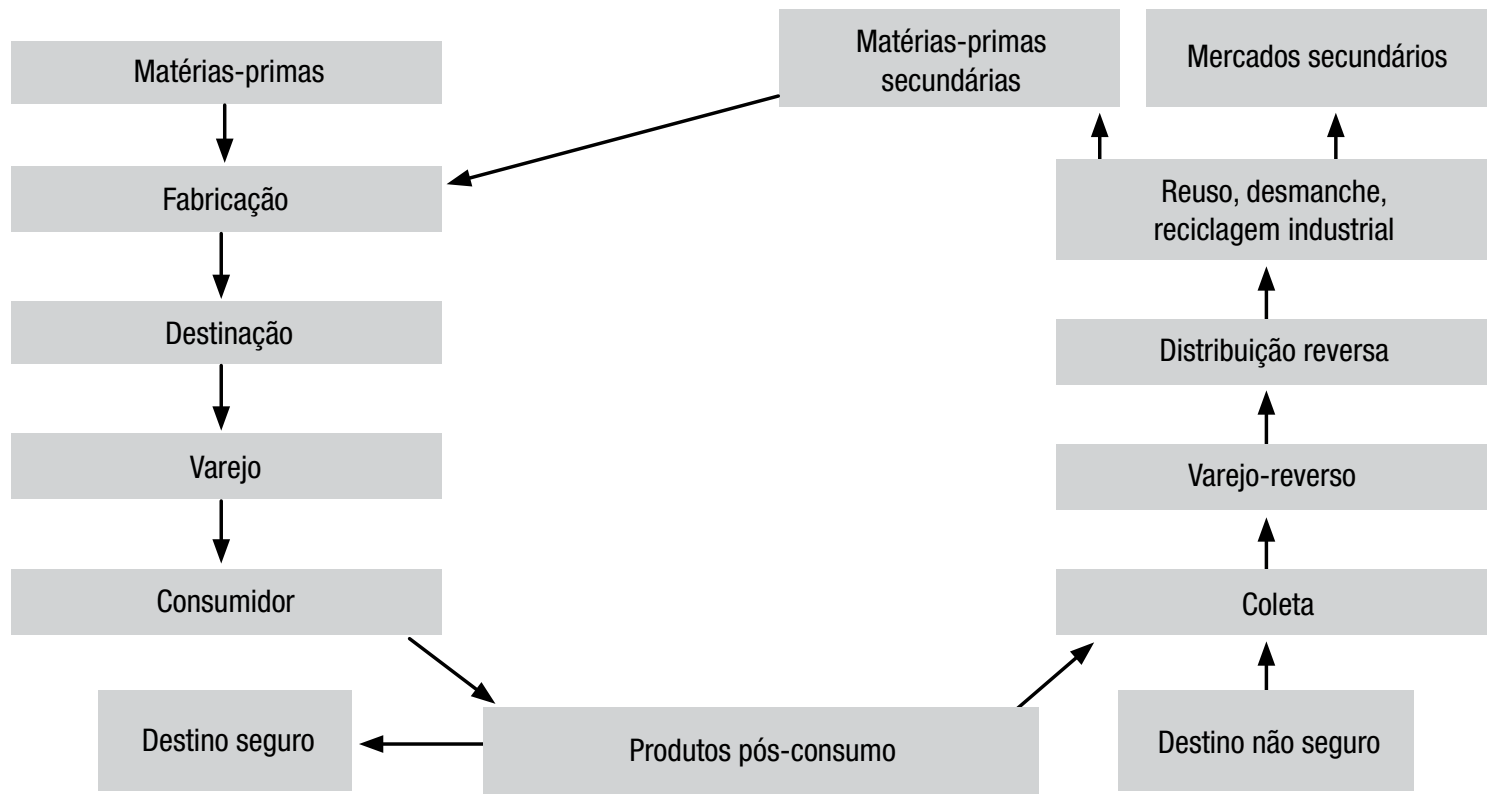


levar os produtos aos consumidores seja substituído por um fluxo que assegure a destinação segura, privilegiando a reinserção do material no processo produtivo da própria empresa ou a comercialização em mercados secundários, conforme apresentado na Figura 1.

Para Leite (2003), a LR potencializa os benefícios econômicos e ambientais das atividades de reúso e reciclagem, uma vez que a maior parte dos materiais pós-consumo apresenta valor agregadado no mercado secundário. Além dessa característica dos resíduos pós-consumo, nos países desenvolvidos, três fatores explicam o maior interesse sobre o tema nos campos da pesquisa e da gestão empresarial: a evolução da legislação ambiental, os benefícios gerados para a imagem da empresa, relacionados a práticas de cidadania corporativa, e as pressões competitivas (8 SHANKAR, TIWARI, 2008; JAYARAMAN e LUO, 2007).

A nova legislação ambiental em países europeus e asiáticos obrigou um número maior de setores empresariais a desenvolver programas de recolhimento de resíduos pós-consumo (RAVI, SHANKAR, TIWARI, 2008). Também, em uma sociedade cada vez mais consciente da relação entre ações empresariais e impactos ambientais, práticas como a da LR melhorariam a imagem das organizações, impactando na participação de mercado. Por fim, as pressões competitivas viriam da necessidade das empresas de reduzir custos. Por tanto, a implantação de um sistema de LR, quando acompanhada de inovação em produtos e processos, pode gerar novas fontes de receita, compensando, muitas vezes, o custo com o investimento inicial feito.

De fato, nos últimos anos, várias empresas recriaram seus processos produtivos de modo a incorporar a LR. Para Stock e Mulki (2009), as empresas que caminham nessa direção estão antecipando as mudanças na legislação ambiental e adequando seus processos ao novo perfil do consumidor, propiciado pela revolução do marketing verde. Além disso, ao priorizar a reutilização e a reciclagem de produtos, reduzem-se o consumo de matéria-prima e a disposição final de resíduos.

Um exemplo de como inovação e LR podem conciliar objetivos econômicos, ambientais e sociais é a indústria de carpetes Interface. A grande inovação do processo da empresa foi o desenvolvimento dos carpetes modulares, possibilitando a retirada de módulos isolados recicláveis em casos de troca do produto ou da realização de serviços de manutenção. O reaproveitamento desse material gerou uma redução de custos de US\$ 372 milhões em 12 anos (DEMAJOROVIC e MATURANA, 2009). Outro exemplo incorporando a LR é o da empresa Recellular. O programa estabelecido pela empresa possibilita a compra de aparelhos usados, que são remodelados para serem vendidos no mercado (JAYARAMAN e LUO, 2007). Aparelhos obsoletos ou danificados são vendidos a empresas recicladoras que recuperam diferentes materiais, como polímeros e metais pesados das baterias. Em 2009, cinco milhões de aparelhos foram reaproveitados, evitando que 800 milhões de quilos de resíduos fossem direcionados para aterros (RECELLULAR NEWS, 2010).

Os exemplos citados indicam o potencial econômico e socioambiental para empresas que adotam um sistema de LR associado à inovação em seus processos e produtos. Ainda assim, muitas empresas acreditam que os custos e a complexidade de se estabelecerem fluxos reversos não compensam o possível retorno financeiro (JAYARAMAN e LUO, 2007). Essa complexidade está associada à necessidade de se estabelecerem novas relações entre os diversos atores da cadeia produtiva, o que exige esforços de coordenação por parte das empresas. Algumas razões para o desinteresse em implantar sistemas de LR são: a dificuldade das empresas em medir o impacto efetivo do retorno de produtos e de o fluxo reverso ser entendido como uma atividade de alto custo paralela às operações usuais da empresa (BRAGA e outros, 2006).

Outro grande desafio para a implantação da LR está na desconsideração dos gestores do papel da comunicação para favorecer o trabalho cooperativo dos atores da cadeia, em especial dos consumidores finais, que se encontram no início do processo de fluxo reverso. Grande parte da ineficácia dos programas de LR pode ser creditada justamente à falta de campanhas eficientes de conscientização, que informem e incentivem as pessoas a encaminharem seus aparelhos e baterias em desuso aos postos de coleta (ESPINOSA e TENÓRIO, 2005). A comunicação é essencial para informar como o consumidor pode se inserir no processo e também servir como um motivador para sua participação. É o caso dos programas de baterias e aparelhos celulares: seu sucesso está diretamente ligado à integração dos consumidores no processo, disponibilizando-se a levar seus aparelhos antigos aos canais de distribuição reversa. Nesse contexto, argumenta-se que uma forma de aumentar a eficácia de programas de LR pode estar em planejar e implementar programas de comunicação orientados pelos princípios da comunicação integrada de marketing (CIM), objetivando mudanças no comportamento dos consumidores. 


\section{COMUNICAÇÃO INTEGRADA DE MARKETING}

\begin{abstract}
A CIM (do inglês integrated marketing communications - IMC) representa o esforço da organização em promover, por meio de ferramentas múltiplas e de maneira unificada, uma mensagem única (SHIMP, 2002). A CIM foi conceituada como um campo formal de estudo no final dos anos 1980 e início dos anos 1990. Surge como uma evolução natural da comunicação de marketing em resposta a mudanças no mercado, na mídia e comunicações e nos consumidores (KLIATCHKO, 2005).

Considera-se a CIM uma tendência prevalecente e irreversível na abordagem de negócios e no planejamento de comunicações de marketing. Praticá-la não seria mais uma escolha, mas uma necessidade para as empresas no mundo todo (KIM, HAN, SCHULTZ, 2004). Se empregada corretamente, a CIM pode ser uma forma de comunicação mais competitiva; especialmente em um ambiente onde a audiência está constantemente exposta a volumes crescentes de mensagens concorrendo por atenção (McGRATH, 2005). Adicionalmente, permitiria gerar uma imagem forte da organização na memória do público ao criar consciência, influenciar atitudes e gerar intenções comportamentais. Portanto, é possível que a comunicação de um programa de LR fundamentada nos princípios da CIM contribua com a sua efetividade, alcançando os resultados almejados. A CIM é um processo de gestão estratégica da comunicação orientado
\end{abstract}

pela audiência e baseado em quatro pilares, como mostra a Figura 2.

O primeiro pilar refere-se aos múltiplos públicos com os quais a empresa interage, incluindo as audiências interna e externa (SCHULTZ e SCHULTZ, 1998). A audiência externa engloba clientes, consumidores, clientes potenciais e outras entidades fora da organização, como órgãos do governo, intermediários e público em geral. Já a audiência interna é formada por empregados, gerentes, diretores, entre outros. O objetivo da comunicação de um programa de LR seria criar consciência, influenciar atitudes e gerar comportamentos, por isso todos os stakeholders, representados pelas audiências, deveriam ser considerados.

O pilar conteúdo abrange mensagens e incentivos do programa de comunicação (SCHULTZ e SCHULTZ, 2004). A mensagem refere-se aos conceitos, ideias ou associações e todos os outros valores e percepções transmitidos aos consumidores. Os incentivos são ofertas de curto prazo ou recompensas ao consumidor por ter feito algo de valor para a empresa e para ele próprio. O conteúdo pode ser controlado, isto é, planejado pelos emissores, e não controlado, ou seja, não planejado e imprevisível (KLIATCHKO, 2008). O primeiro deve ser não só relevante, mas criativo, persuasivo, consistente, e respeitar os valores da audiência (KLIATCHKO, 2004). Nessa linha, o conteúdo da mensagem para comunicar um programa de LR deveria ser permeado por essas características. Já o conteúdo não planejado ou espontâneo, como o boca a boca, deveria ser gerido e incentivado.

\section{Figura 2 - Os pilares da CIM}

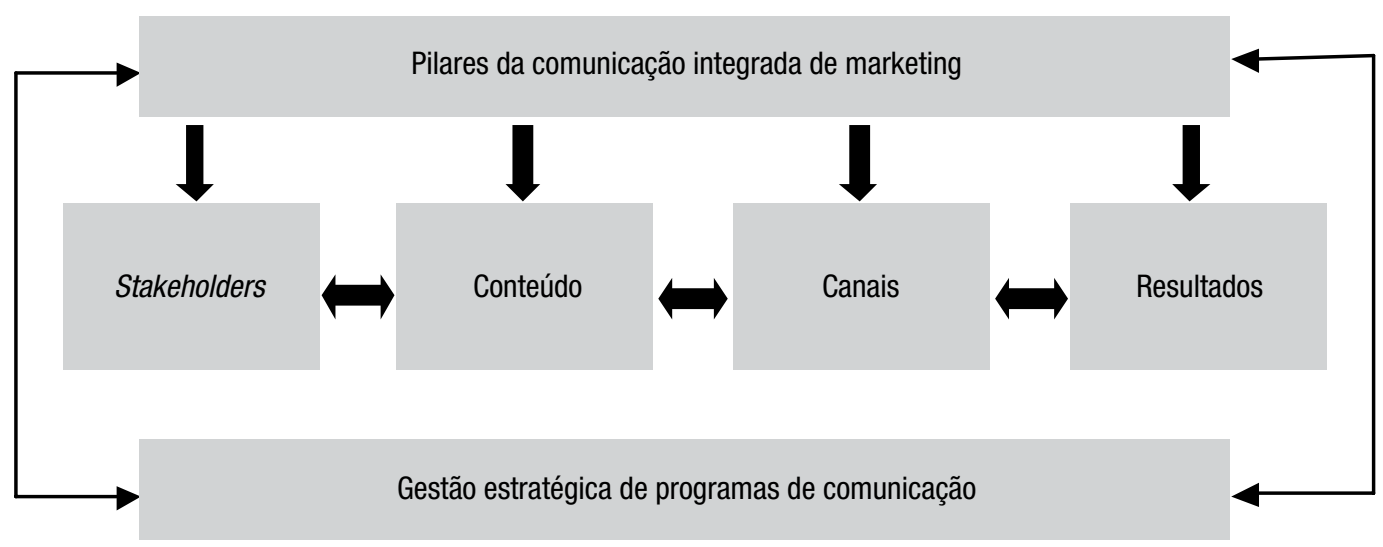


O pilar canais expande o conceito tradicional, pois considera aqueles canais que não eram entendidos como tais no passado (SCHULTZ e SCHULTZ, 1998). Isto é, abrange todos os pontos de contato possíveis para que o consumidor esteja exposto à mensagem. As considerações para a escolha de canais são: relevância e preferência (SCHULTZ e SCHULTZ, 2004). Isso significa que, contrariamente a tentar atingir a audiência por todos os canais possíveis, deve-se optar pelos que serão mais efetivos para alcançar o público-alvo. Tratando-se da comunicação de um programa de LR, diversos canais, como website da empresa, televisão, rádio, revistas e canais de comunicação direta, como o Serviço de Atendimento ao Consumidor (SAC), poderiam ser utilizados. Por outro lado, hoje, o comportamento de consumo de conteúdo é controlado pelo receptor, que decide o que quer receber ou criar, de acordo com a sua conveniência (FOOTE, 2005). Nesse sentido, a empresa deve estar preparada para, por meio de diversos canais, oferecer o conteúdo que a audiência procura. Ou seja, o indivíduo interessado em informações sobre descarte de produtos pós-consumo de um programa de LR deveria encontrá-las facilmente.

O pilar resultados da CIM foca a avaliação do programa de comunicação nas respostas comportamentais da audiência e nos resultados financeiros (SCHULTZ e WALTERS, 1997). Do ponto de vista financeiro, os resultados são mensurados pelo retorno sobre investimento no consumidor ou ROCI (do inglês returns-on-customer investments), ou seja, pelas vendas incrementais alcançadas em função do investimento em comunicação voltada a consumidores específicos. Por outro lado, as respostas comportamentais não implicam necessariamente a compra de um produto. Por exemplo, ao se comunicar um programa LR, não se espera que o consumidor faça uma compra, mas sim que adote um determinado comportamento. Por isso, nesse caso, a avaliação dos resultados da comunicação de um programa de LR estaria na avaliação da mudança de comportamento dos consumidores.

Com base nos quantro pilares, o objetivo da CIM é produzir uma campanha global visando um resultado sinérgico entre a imagem construída da marca e a resposta comportamental do público-alvo (KLIATCHKO, 2005). Sendo assim, planejar a comunicação de um programa de LR de acordo com os princípios da CIM parece ser a estratégia mais adequada. Isso, aliado ao pouco conhecimento sobre como as empresas comunicam seus programas de LR no Brasil, faz com que seja oportuno o levantamento de dados empíricos.

\section{MÉTODO DA PESQUISA}

Diante do objetivo proposto de se fazer um diagnóstico da comunicação de programas de LR de empresas fabricantes de celulares atuantes no Brasil, realizou-se uma pesquisa exploratória em duas frentes. A Figura 3 ilustra o esquema da pesquisa à luz do referencial teórico discutido.

De um lado, aparecem os pilares da CIM e, do outro, as frentes da pesquisa. A primeira delas procurou avaliar o pilar conteúdo da CIM, analisando as informações sobre descarte de celulares e baterias repassadas pela empresa, da perspectiva do consumidor (um elemento do pilar stakeholder) e em vários canais (website, correio eletrônico, SAC, assistência técnica e lojas de operadores de telefonia móvel; elementos do pilar canal). A segunda frente da pesquisa abordou o pilar resultados da CIM, avaliando comportamento e conhecimento do consumidor com relação ao descarte de celulares e baterias. Foram escolhidas para fazer parte da pesquisa empresas líderes do mercado brasileiro na fabricação de aparelhos celulares e suas respectivas baterias. São elas: Nokia, Samsung, LG, Sony Ericson e Motorola.

O Quadro 1 traz os elementos da pesquisa, as técnicas e os instrumentos de coleta de dados utilizados.

Para a análise dos websites, optou-se pela análise de conteúdo, com apoio de um codificador contendo as informações a serem procuradas (Quadro 2). A construção do codificador considerou as informações que a Lei n. 12.305 obriga as empresas a disponibilizar aos consumidores sobre produtos e programas de LR. Entre elas, destacam-se: instruções sobre descarte de celulares e baterias, destino do material recolhido, explicações sobre os prejuízos do descarte inadequado e os benefícios da reciclagem. Três estudantes de graduação em administração participaram simultânea e separadamente da análise de todos os websites. Para o registro dos resultados da análise dos websites, utilizou-se uma planilha Excel. Depois, os resultados foram comparados e as divergências, resolvidas por um juiz. A média de coincidência entre os dois avaliadores foi de $98 \%$, o que garante a validade do codificador utilizado. As discrepâncias foram relacionadas à dificuldade de encontrar as informações procuradas.

Para a coleta de dados no canal correio eletrônico, optou-se por realizar entrevistas pela própria via, com funcionários das empresas fabricantes de celulares e baterias. O endereço eletrônico de envio foi o disponibilizado nos websites das cinco empresas analisadas. O roteiro repassado continha a solicitação de informa- 
ções sobre a existência de programas de LR, descarte e destino de celulares e baterias, bem como sobre conhecimento da Lei n. 12.305. O mesmo roteiro foi utilizado nas entrevistas nos canais SAC (via telefone), assistência técnica e loja de operadora de telefonia móvel (via contato pessoal). Nos dois últimos, os funcionários entrevistados foram os das empresas autorizadas pelas fabricantes a prestar serviços de assistência técnica de celulares e os das lojas de quatro operadoras, incluindo TIM, Claro, Vivo e Oi. De modo a não influenciar as respostas dos entrevistados, optou-se por não informar tratar-se de uma pesquisa. Os entrevistadores colocaram-se no papel de clientes procurando informações. Todos os respondentes ocupavam o cargo de atendentes, tendo sido contactados aleatoriamente.

$\mathrm{Na}$ segunda frente da pesquisa, aplicou-se pessoalmente um questionário estruturado a uma amostra de consumidores. Buscou-se saber sobre procedimentos adotados no descarte de aparelhos e baterias pós-consumo. Outras questões avaliaram a iniciativa dos consumidores para buscar informações sobre o descarte correto. Para tanto, perguntou-se sobre os meios procurados para obtenção de informações, a qualidade das informações obtidas, o conhecimento da Lei n. 12.305 e os danos causados pela disposição de baterias no meio ambiente. Adicionalmente, a intenção comportamental de compra em relação às empresas que se preocupam com o descarte correto foi levantada.

\section{Figura 3 - Os pilares da CIM e as frentes da pesquisa}

Pilares da CIM

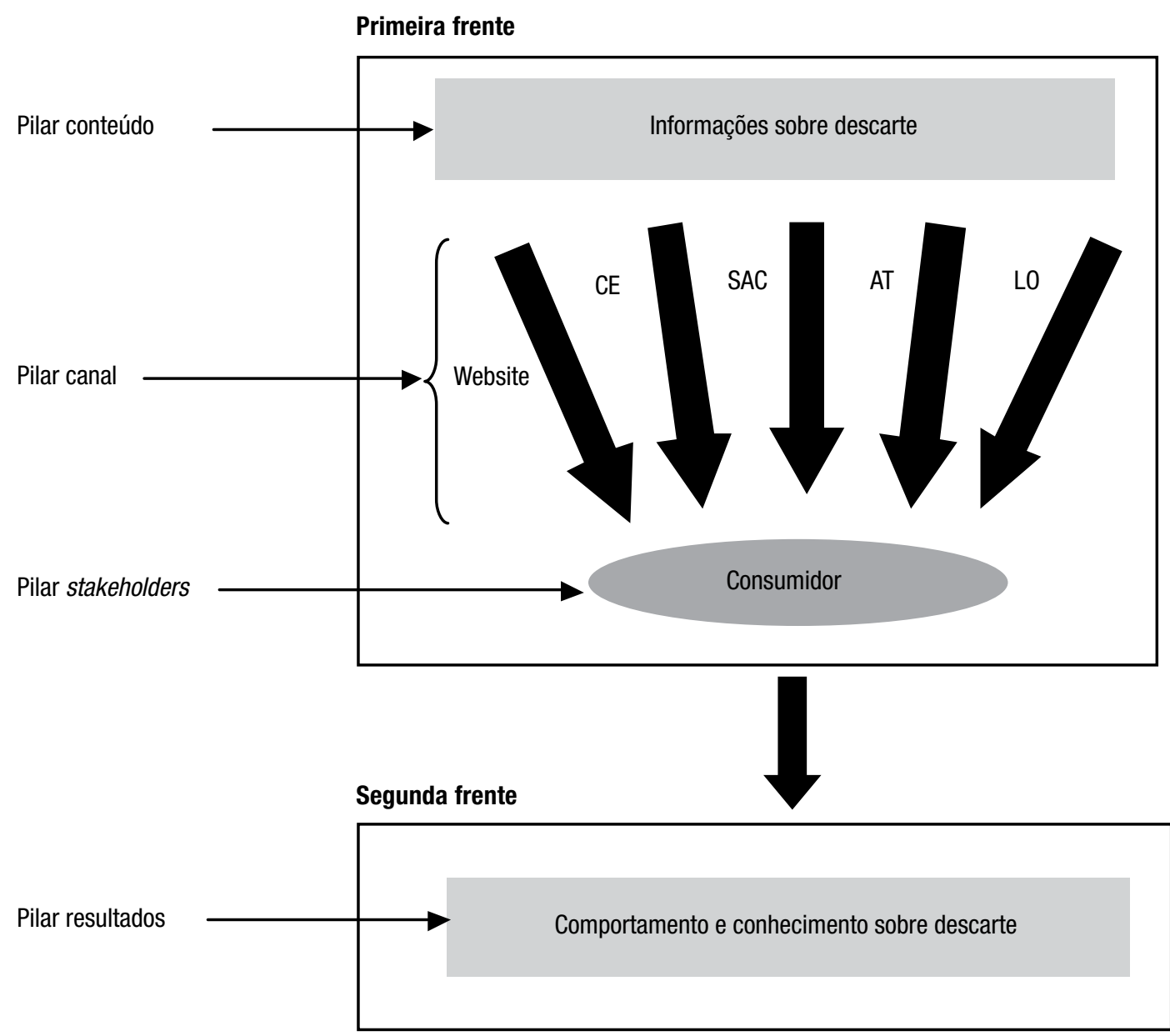


Também, perguntou-se pelos sacrifícios passíveis de serem assumidos para o descarte correto, como distância percorrida e tempo gasto. Por último, indagou-se sobre a motivação para adotar o comportamento correto, avaliando-se o possível efeito de utilização de estímulos pela empresa fabricante.

\section{RESULTADOS}

A seguir, apresentam-se os resultados da pesquisa de campo em cada um dos elementos pesquisados.

\section{Resultados do canal website}

De acordo com o Quadro 2, a análise dos websites revela que nenhuma das empresas pesquisadas menciona espontaneamente qualquer tipo de informação sobre LR e descarte, seja de baterias ou celulares. Já quando esse tipo de informação foi procurada na opção busca de cada website, apenas Motorola, Nokia e Sony Ericsson geraram resultados. Nos websites da LG e da Samsung, não houve resposta para as buscas realizadas.

Encontraram-se no site da Nokia informações sobre o programa de reciclagem da empresa, o Alô Recicle, que envolve uma parceria com o Pão de Açúcar para recolhimento de celulares e baterias. A Motorola conta com o programa Ecomoto desde 2007, recolhendo os produtos por meio das autorizadas. A Sony Ericsson apresenta o programa Takeback, porém ainda não está implantado no Brasil. Nos sites da Samsung e LG, não aparecem informações sobre programas para descarte e reciclagem de baterias. Nos sites da Motorola e da Nokia, foram encontrados os endereços dos locais para descarte.

A Nokia é a única empresa que detalha a destinação dos produtos recolhidos. Explica-se, no website, o que é feito com cada parte do aparelho após a desmontagem

\section{Quadro 1 - Unidades de pesquisa, técnicas e instrumentos de coleta de dados}

\begin{tabular}{|c|c|c|}
\hline Elementos de pesquisa & Técnicas & Instrumentos \\
\hline \multicolumn{3}{|c|}{ Primeira frente da pesquisa } \\
\hline Website & $\begin{array}{l}\text { Análise de conteúdo } \\
\text { Junto aos websites das empresas } \\
\text { fabricantes }\end{array}$ & $\begin{array}{l}\text { Codificador } \\
\text { LR, descarte de baterias, possíveis danos gerados ao meio } \\
\text { ambiente, estímulo ao consumidor, locais de descarte, } \\
\text { destino do material devolvido, efeitos prejudiciais do } \\
\text { descarte inadequado, benefícios da reciclagem }\end{array}$ \\
\hline Correio eletrônico & $\begin{array}{l}\text { Entrevista } \\
\text { Com funcionários (atendentes) das } \\
\text { empresas fabricantes, via correio } \\
\text { eletrônico ( } 2 \text { de cada empresa) }\end{array}$ & $\begin{array}{l}\text { Roteiro } \\
\text { Existência de programas de LR } \\
\text { Informações fornecidas ao consumidor sobre descarte e } \\
\text { destino dos produtos } \\
\text { Conhecimento da lei }\end{array}$ \\
\hline $\begin{array}{l}\text { Serviço de atendimento ao } \\
\text { consumidor }\end{array}$ & $\begin{array}{l}\text { Entrevista } \\
\text { Com funcionários (atendentes) das } \\
\text { empresas fabricantes, via telefone } \\
\text { ( } 2 \text { de cada empresa) }\end{array}$ & $\begin{array}{l}\text { Roteiro } \\
\text { Existência de programas de LR } \\
\text { Informações fornecidas ao consumidor sobre descarte e } \\
\text { destino dos produtos } \\
\text { Conhecimento da lei }\end{array}$ \\
\hline $\begin{array}{l}\text { Assistência técnica e loja de } \\
\text { operadora de telefonia móvel }\end{array}$ & $\begin{array}{l}\text { Entrevista } \\
\text { Com funcionários (atendentes) de } \\
\text { autorizadas ( } 2 \text { de cada empresa) e de } \\
\text { lojas de operadoras (atendentes), via } \\
\text { contato pessoal ( } 2 \text { de cada empresa) }\end{array}$ & $\begin{array}{l}\text { Roteiro } \\
\text { Existência de programas de LR } \\
\text { Informações fornecidas ao consumidor sobre descarte e } \\
\text { destino dos produtos } \\
\text { Conhecimento da lei }\end{array}$ \\
\hline \multicolumn{3}{|c|}{ Segunda frente da pesquisa } \\
\hline Consumidor & $\begin{array}{l}\text { Levantamento } \\
\text { Com consumidores, via contato } \\
\text { pessoal ( } 44 \text { indivíduos) }\end{array}$ & $\begin{array}{l}\text { Questionário } \\
\text { Perguntas fechadas sobre ações e conhecimento } \\
\text { relacionados ao risco do produto, formas de destinação e } \\
\text { avaliação das informações disponibilizadas pelas empresas }\end{array}$ \\
\hline
\end{tabular}


e reciclagem. As baterias seriam reutilizadas na fabricação de novas baterias, alto-falantes e aço inoxidável. Os componentes transformam-se em joias, equipamentos eletrônicos, aplicações médicas e dentais. As capas dos celulares são transformadas em cones de trânsito e plástico reciclado. Nos sites da Motorola e Sony Ericsson, não foram encontradas informações sobre a destinação final após a reciclagem. Nenhum dos websites presta esclarecimentos sobre prejuízos causados pelo descarte inadequado de baterias e celulares no meio ambiente. Apenas são apresentadas informações sobre os beneficios da reciclagem.

A Nokia sustenta que, com a reciclagem, não é preciso extrair e refinar tanto material para produzir novos produtos. Dessa maneira, economizar-se-iam energia, produtos químicos e resíduos. Os projetistas da empresa tentariam garantir que um novo aparelho cause o mínimo de impacto possível no planeta (e seus habitantes), produzindo aparelhos ecologicamente corretos. A Sony Ericsson afirma, em seu website, que o retorno e reciclagem dos produtos que completaram seus ciclos de vida é uma parte importante da conservação dos recursos naturais. A empresa estimula a reciclagem e o retorno dos produtos, uma vez que os componentes e materiais podem ser extraídos e reutilizados em outras aplicações, reduzindo-se, assim, a sobrecarga ambiental. Com o tratamento adequado de baterias e celulares descartados, a Sony aponta que uma grande quantidade de materiais pode ser recuperada e reciclada, minimizando ou eliminando as perdas e emissões indesejadas para o ambiente ao nosso redor.

A Motorola afirma contribuir com o desenvolvimento sustentável do País ao inovar no uso de materiais ambientalmente corretos, que podem ser facilmente reciclados, e ao priorizar o design de produtos que facilitem o reaproveitamento. Como consequência, segundo a empresa, o impacto ambiental seria reduzido em cada fase do ciclo de vida (projeto, fabricação, distribuição, utilização e fim de vida). Quanto a materiais que não podem ser reutilizados, a Motorola diz que podem ser reciclados, reduzindo-se o desperdício e o uso de matérias-primas para fazer novos telefones. A empresa LG não disponibliza qualquer informação sobre os benefícios da reciclagem dos aparelhos e baterias.

\section{Resultados do canal correio eletrônico}

$\mathrm{Na}$ pesquisa via correio eletrônico, obtiveram-se os seguintes resultados: a Sony Ericsson retornou o e-mail após três dias, não respondeu ao questionamento e apenas anexou uma lista de endereços das assistências técnicas, orientando o descarte de aparelhos celulares e baterias em algum desses locais. A LG respondeu no mesmo dia, porém também não foi obtido qualquer tipo de informação em relação às perguntas

\begin{tabular}{|c|c|c|c|c|c|}
\hline Informações sobre... & Nokia & Sony Ericsson & Motorola & LG & Samsung \\
\hline \multicolumn{6}{|l|}{ LR na página inicial } \\
\hline \multicolumn{6}{|l|}{ Descarte de baterias na página inicial } \\
\hline \multicolumn{6}{|l|}{ Descarte de celulares na página inicial } \\
\hline Descarte de baterias na ferramenta de busca do site & Sim & Sim & Sim & & \\
\hline Descarte de celulares na ferramenta de busca do site & Sim & Sim & Sim & & \\
\hline Reciclagem de baterias na ferramenta de busca do site & Sim & $\operatorname{Sim}$ & Sim & & \\
\hline Reciclagem de celulares na ferramenta de busca do site & Sim & Sim & Sim & & \\
\hline Seus próprios programas de LR & Sim & $\operatorname{Sim}$ & $\operatorname{Sim}$ & & \\
\hline Locais de descarte (celulares e baterias) & $\operatorname{Sim}$ & & $\operatorname{Sim}$ & & \\
\hline Destinação dos produtos coletados & Sim & & & & \\
\hline \multicolumn{6}{|c|}{ Efeitos prejudiciais do descarte inadequado de baterias e celulares } \\
\hline Benefícios da reciclagem para o meio ambiente & Sim & Sim & Sim & & \\
\hline
\end{tabular}


enviadas, restrigindo-se a informar pontos de coleta para descarte. A empresa Motorola não respondeu ao e-mail enviado. A Samsung retornou o e-mail três dias após o envio, e nele a empresa manifestou: "a legislação nacional prevê que baterias compostas de metais ditos pesados - que são tóxicos e nocivos à saúde - devam ser recolhidas pelos fabricantes para posterior eliminação. A Samsung, preocupada com a preservação do meio ambiente, adotou, desde o início de suas operações com celulares no Brasil, baterias de princípios químicos não tóxicos ou nocivos, sendo de íons de lítio (Li-íon). Essas baterias não se enquadram na legislação que determina o seu recolhimento. Ainda assim, a Samsung, preventivamente, orienta seus clientes a encaminhar as baterias usadas às assistências técnicas autorizadas para que a empresa providencie o seu descarte apropriado". Juntamente com a manifestação da empresa, estava o link da lista com os endereços dos postos de coleta.

A Nokia retornou o e-mail após três dias, sendo a única empresa que apresentou respostas às questões feitas no e-mail. Manifestou-se da seguinte forma: "O Programa de Reciclagem de Baterias Nokia consiste da coleta de baterias inutilizadas por meio de urnas disponibilizadas nas lojas das operadoras e nas assistências técnicas autorizadas. Posteriormente, elas são armazenadas e enviadas a uma empresa que atua internacionalmente na área de processamento de baterias. Grande parte dos resíduos é transformada em energia elétrica e aço inoxidável. A Nokia Brasil tem grande preocupação com o meio ambiente e preocupa-se em coletar e encaminhar para reciclagem as baterias que fabrica, seguindo as orientações do Conselho Nacional do Meio Ambiente".

Observa-se que, entre as empresas pesquisadas, a Nokia, como ocorrido na avaliação dos websites, é a empresa que, também por correio eletrônico, forneceu as informações mais completas em relação aos questionamentos apresentados.

\section{Resultados do canal SAC}

Aqui foram entrevistados funcionários de algumas empresas da rede de assistência técnica autorizada pelas fabricantes e de algumas lojas de operadoras de telefonia móvel. O mesmo roteiro de perguntas utilizado via correio eletrônico foi aplicado via telefone a funcionários das empresas fabricantes. Todas as empresas não deram qualquer tipo de esclarecimento sobre os questionamentos, apenas recomen- daram a procura pessoal das assistências técnicas para obtenção de mais informações.

\section{Resultados dos canais assistência técnica e loja de operadora}

Para a realização dessa etapa, foram feitas visitas presenciais a duas assistências técnicas indicadas por cada empresa (LG, Nokia, Samsung, Motorola e Sony Ericsson) e duas lojas de cada operadora de telefonia celular (Claro, Oi, Tim e Vivo). As assistências técnicas demonstraram não ter preparo para responder a questões sobre programas de LR e descarte de aparelhos e baterias, bem como conhecimento sobre a legislação vigente. Os funcionários das empresas não possuem conhecimento do que é feito com os aparelhos e baterias após o descarte. Não existe nenhum tipo de registro do descarte dos aparelhos e baterias após o término de sua vida útil, o procedimento é somente efetuar o depósito na urna ou caixa. As assistências alegam que há uma empresa terceirizada que faz o recolhimento periodicamente, sem determinar a periodicidade de retiradas nem o nome da empresa responsável. Algumas das assistências técnicas não continham nenhum tipo de comunicação, nem mesmo local para descarte. Especificamente, uma das assistências técnicas indicadas pelas empresas LG e Samsung solicitou que o descarte fosse efetuado na videolocadora do prédio ao lado, pois havia um local para descarte. Nas lojas das operadoras, havia uma urna de $20 \times 20 \mathrm{~cm}$ ou uma caixa de plástico de $30 \times 30 \mathrm{~cm}$ para o descarte, com um pequeno e discreto aviso indicando, como local para descarte, o próprio recipiente.

\section{Resultados do consumidor}

Responderam ao questionário 44 indivíduos. Os resultados sobre o comportamento do consumidor quanto ao descarte dos aparelhos celulares e baterias indicam que $14 \%$ o fizeram no lixo doméstico, $64 \%$ têm os produtos guardados em casa e $22 \%$ os descartaram em pontos de coleta. Apenas 29\% buscaram informações sobre o descarte correto e $71 \%$ não se preocuparam. Entre os que procuraram obter informações, 54\% o fizeram nos websites das empresas fabricantes, $15 \%$, no SAC via telefone e $23 \%$, na loja da operadora de telefonia móvel.

Todos os entrevistados têm conhecimento sobre as consequências prejudiciais ao meio ambiente do descarte incorreto de baterias e aparelhos, porém $84 \%$ deles não sabem sobre a nova lei e apenas 16\% 
têm consciência de sua existência. Sobre os sacrifícios com os quais os consumidores estão dispostos a arcar para descartar produtos de maneira correta, 77\% responderam que estariam dispostos a deslocar-se até os pontos de coleta. Para 66\% dos consumidores, é um fator decisivo, para sua próxima compra, saber que a empresa fabricante se preocupa com o descarte correto. Já 34\% admitem não ser um critério de seleção e decisão a ser considerado em futuras compras. Por fim, sobre possíveis estímulos para incentivar a participação do consumidor em programas de LR, todos os consumidores afirmam que levariam seus aparelhos em desuso na hora de comprar um novo, caso as empresas oferecessem descontos na aquisição do novo aparelho.

\section{CONCLUSÕES}

O objetivo desta pesquisa foi fazer um diagnóstico da comunicação de programas de LR de empresas fabricantes de celulares atuantes no Brasil. Os resultados evidenciam que, na prática, as empresas investigadas não estão alinhadas com a legislação vigente. Nenhum dos websites analisados apresenta espontaneamente informações sobre LR ou descarte de aparelhos e baterias. De modo geral, nenhum dos projetos de LR está preparado para operacionalizar efetivamente o retorno dos produtos pós-consumo. Comprovou-se que as informações não estão integradas entre os canais, de modo que se consigam consistência e efetividade dos programas das empresas, como nos casos específicos da Nokia, com o programa Alô Recicle, e da Motorola, com o Ecomoto.

Observou-se que as mensagens repassadas pelos canais não operam de modo eficiente, contribuindo com a divulgação de uma mensagem unificada que facilite a conscientização e o entendimento do consumidor quanto ao comportamento correto para o descarte das baterias e celulares. O fato de a grande maioria de produtos em desuso estar armazenada na casa dos respondentes ou ter sido descartada no lixo doméstico evidencia falhas nos programas de comunicação.

Os resultados indicam que as empresas não realizam de maneira eficiente a gestão de comunicação com seus públicos internos (funcionários) e externos (assistências técnicas, distribuidores autorizados, operadoras). Esses públicos foram aqui analisados como canais de comunicação com o consumidor, mas, de acordo com a CIM, são também stakeholders com os quais a empresa deveria realizar uma comunicação unificada e direta. O ideal seria que os públicos contribuíssem para a eficácia da implementação das estratégias corporativas, neste caso, dos programas de LR.

Os resultados confirmam a afirmação de Souza, Santos e Lima (2007) postulando que não adianta só possuir canais reversos, pois eles não funcionarão corretamente se as informações sobre a forma de retorno não forem plenamente divulgadas. Esse parece o caso da Nokia e da Motorola, pois, apesar de terem programas de LR, falhas na comunicação não permitem sua implementação. A informação não flui corretamente entre os diversos membros da parte da cadeia produtiva analisada, prejudicando o engajamento do seu principal ator, que é o consumidor. Por falta de informações, o consumidor, que é o ponto de partida do fluxo reverso, impossibilita que o processo funcione adequadamente. A responsabilidade de retorno de aparelhos e baterias recai sobre o usuário, porém este, desinformado, não cumprirá sua função na cadeia de reciclagem, guardando os produtos em casa ou jogando-os no lixo doméstico (SOUZA, SANTOS, LIMA, 2007). Nos casos da LG e Samsung, o problema é potencializado em função da inexistência de programas de LR. Já na Sony Ericsson, apesar de divulgar o programa Takeback, ele ainda não está implantado no Brasil.

As entrevistas feitas diretamente com funcionários das empresas fabricantes mostram que aquelas que divulgam nos websites seus programas de LR, como a Nokia e a Motorola, não disponibilizam as mesmas informações via correio eletrônico nem no SAC via telefone. Os responsáveis por esse serviço são despreparados para responder a qualquer pergunta sobre os programas divulgados nos websites ou repassar informações de incentivo para que os consumidores façam a disposição correta nos postos de coleta. Partiu-se da premissa de que ambos os canais eram operados por funcionários da empresa fabricante, mas é possível que esses serviços sejam realizados por empresas terceirizadas, o que explicaria a falta de conhecimento sobre os programas. Sendo assim, caberia ao fabricante buscar formas de treinar os responsáveis para que possam ser passadas as informações necessárias. Os canais que permitem que o consumidor entre em contato direto e pessoalmente com a empresa são deficitários e não estão preparados para fornecer qualquer informação relevante a respeito de possíveis questionamentos sobre LR.

Como procedimento padrão, as respostas via correio eletrônico e todos os SAC indicaram procurar as assistências técnicas autorizadas como forma de obtenção de mais informações. Porém, como resultado da 
pesquisa com as autorizadas, observou-se que os funcionários destas também não são capazes de repassar nem sequer as informações encontradas nos websites das fabricantes ou fornecer ao consumidor respostas quanto à destinação das baterias coletadas. A análise revela que as informações entre as fabricantes de aparelhos e suas respectivas assistências técnicas cadastradas, do mesmo modo que nas lojas de operadoras de telefonia móvel, não estão alinhadas.

As deficiências da comunicação nos programas da Nokia e da Motorola e a inexistência deles na Sony Ericsson, LG e Samsung indicam que a LR não é entendida como fonte de vantagem competitiva, como defendem Jayamaran e Luo (2007) e Ravi, Shankar e Tiwari (2008). Destaca-se o fato de as empresas não utilizarem a comunicação de maneira integrada entre os canais, com o intuito de divulgar os programas existentes e obter ganhos na construção da imagem da empresa voltada ao desenvolvimento sustentável. Adicionalmente, as empresas não oferecem benefícios financeiros em troca dos aparelhos obsoletos, como desconto na compra de um novo, o que também poderia gerar vantagem competitiva.

Da pesquisa com o consumidor, é possível inferir que as empresas estão perdendo a oportunidade de fidelizar o cliente em relação à marca. Encontrou-se que $100 \%$ dos consumidores levariam seus aparelhos usados, no ato da compra, caso este fosse revertido em algum tipo de beneficio na aquisição de um novo. Numa visão mais abrangente, a gestão das empresas deveria levar em consideração o modelo de marketing de relacionamento baseado em comunicação (DUNCAN e MORIARTY, 1998), em que a ênfase é na comunicação de duas vias, compartilhamento de informação, feedback oportuno, escutar e responder a clientes, prospectos e outros stakeholders. Essas seriam atividades, e não só a oferta de incentivos, que fortaleceriam os relacionamentos.

A avaliação das informações sobre LR nos diferentes canais de comunicação das empresas na perspectiva do consumidor mostra que nenhuma delas tem se guiado pelos princípios da CIM, não potencializando o resultado de seus programas. O processo da CIM deve enfatizar a coordenação de seus pilares, incluindo todos os pontos de contato possíveis (canais), a entrega de uma mensagem clara e consistente (conteúdo) para uma comunicação de máximo impacto, sendo o objetivo final, além de resultados financeiros, conseguir respostas comportamentais dos públicos-alvo (stakeholders) (KLIATCHKO, 2008). O panorama encontrado configura uma realidade cheia de desafios para as empresas fabricantes, que de- vem se adequar à nova lei sobre descarte de produtos vigente no Brasil. Os princípios da CIM podem ser uma orientação estratégica viável, implicando novos olhares para questões téoricas e práticas da LR.

A LR demanda o planejamento cuidadoso da disponibilização de informações na cadeia. A Política Nacional de Resíduos Sólidos instituiu, na gestão do ciclo de vida dos produtos, a responsabilização compartilhada entre o poder público, produtores, distribuidores e consumidores. Argumenta-se, com base nos resultados desta pesquisa, que o maior desafio para concretizar o fluxo reverso de aparelhos celulares e baterias está na mudança comportamental dos integrantes da cadeia, especialmente do consumidor final. A pesquisa revelou um descompasso entre a intenção comportamental e o comportamento dos consumidores, potencializado pelo desconhecimento da lei e pela falta de informações nos canais de que eles dispõem, como websites e SAC das fabricantes, assistencias técnicas e lojas das operadoras.

As várias implicações teóricas até aqui discutidas estão condensadas na Figura 4. Elas podem ser a base para a construção de um modelo de planejamento e implantação de programas de LR, incorporando os princípios da CIM. Na figura, o elemento central é o fabricante, que tem como principais stakeholders o poder público, a própria empresa fabricante, o varejo e o consumidor. As setas largas entre eles representam o compartilhamento de responsabilidades, bem como possíveis influências recíprocas. Nas laterais, encontram-se o que denominamos pilares de um programa de LR: conteúdo e produtos, ambos permeando todos os elementos de parte da cadeia produtiva e do poder público. Ambos os pilares apresentam caráter dinâmico. Por exemplo, ainda que seja do fabricante a responsabilidade de gerar o conteúdo (parte controlada, segundo Kliatchko, 2008), esse processo é influenciado pela ação do poder público, bem como pelo feedback dos consumidores e do varejo (parte não controlada). O mesmo ocorre com o pilar produto, o avanço da legislação, os elementos da cadeia, a interação entre eles e o maior engajamento do consumidor afetariam qualitativamente e quantitativamente os produtos inseridos em programas de LR. As setas mostram o fluxo que seguiriam tanto o conteúdo quanto os produtos na implementação do programa. As setas ponteadas representam o fluxo direto e as contínuas, o fluxo reverso. Destaca-se o papel do consumidor como ponto de partida do fluxo reverso. O resultado do programa de LR está na mudança do comportamento do consumidor, viabilizando o processo de retorno dos produtos pós-consumo. 
Por fim, algumas limitações devem ser sanadas em pesquisas futuras, como fazer levantamentos com todos os stakeholders e canais de comunicação atuantes em toda a cadeia produtiva. Também por se tratar de uma pesquisa exploratória, os resultados não podem ser generalizados para o todo da indústria pesquisada, ainda que as empresas estudadas sejam as mais importantes do setor.

Um elemento a se considerar para futuras pesquisas é a integração da comunicação com incentivos monetários. A concordância de todos os entrevistados com esse ponto reforça a necessidade de aprofundamento desse tema. Como afirma Santopietro (1995), indivíduos tendem a responder positivamente a um estímulo para a sua mudança de comportamento quando consideram seu custo pessoal baixo. Esse provavelmente é o caso da devolução de aparelhos celulares por parte do consumidor. Assim, uma comunicação que informe como ele pode encaminhar seus resíduos pós-consumo e valorize sua participação como corresponsável na mitigação de danos socioambientais, associado a algum incentivo econômi- co, potencializaria a devolução de aparelhos e baterias.

Nesse contexto, a integração de marketing e sustentabilidade pode ir além da oferta de produtos verdes ou da construção de uma imagem socialmente responsável, beneficiando a sociedade como um todo. O marketing, ao disponibilizar informações ao consumidor, como no caso da LR, ademais de ser um importante instrumento de conscientização, pode estimular ações comportamentais sustentáveis.

\section{REFERÊNCIAS}

ANATEL - Agência Nacional de Telecomunicações. Disponível em: http://www.anatel.gov.br/Portal/exibirPortalInternet.do\#. Acesso em 15.05.2010.

BERNON, M; CULLEN, J. An integrated approach to managing reverse logistics. International Journal of Logistics: Research and Applications, v. 10, n. 1, p. 41-56, 2007.

\section{Figura 4 - Implicações para construção do modelo de planejamento e implantação de programas de LR}




BOWERSOX, D. J; CLOSS, D. J. Logistical management: the integrated supply chain process. Singapura: McGraw-Hill, 1996.

BRAGA JUNIOR, S.S; COSTA, P. R.; MERLO, E. M. Logística reversa como alternativa de ganho para o varejo: um estudo de caso em um supermercado de médio porte. Anais do IX Simpósio de Administração da Produção, Logística e Operações Internacionais: Simpoi 2006. São Paulo: FGV-EAESP, 2006.

DEMAJOROVIC, J; MATURANA, L. M. Desenvolvimento de produtos sustentáveis: purificadores de água Brastemp e carpetes Interface. Revista de Gestão Social e Ambiental, v. 3, n. 3, p. 102-119, 2009.

DUNCAN, T; MORIARTY, S. E. A communication-based marketing model for managing relationships. Journal of Marketing, v. 62, n. 2, p. 1-13, 1998.

ESPINOSA, D. C. R; TENÓRIO, J. A. S. Reciclagem de baterias: análise da situação atual no Brasil. Revista Brasileira de Ciências Ambientais, n. 2, 2005. Disponível em: http:// www.ictr.org.br/ictr/images/online/02_artigo_2.pdf. Acesso em 05.07.2010.

FOOTE, N. Fast forward to the future of TV. Admap, v. 40, n. 11, p. $24-26,2005$.

JAYARAMAN, V; LUO, Y. Creating competitive advantages through new value creation: e reverse logistics perspective. Academy Management Perspective, v. 1, Issue 2, p. 56-73, 2007.

KIM, I; HAN, D; SCHULTZ, D. E. Understnading the difussion of integrated marketing communications. Journal of Advertising Research, v. 44, n. 1, p. 31-45, 2004.

KLIATCHKO, J. Towards a new definition of integrated marketing communications (IMC). International Journal of Advertising, v. 24, n. 1, p. 7-34, 2005.

KLIATCHKO, J. Revisiting the IMC construct: a revised definition and four pillars. International Journal of Advertising, v. 27, n. 1, p. 133-160, 2008.

LEITE, P. R. LR: meio ambiente e competitividade. São Paulo: Prentice-Hall, 2003.

McGRATH, J. M. IMC at a crossroads: a theoretical review and conceptual framework for testing. The Marketing Management Journal, v. 15, n. 2, p. 55-66, 2005.
MUELLER, C. F. LR: meio ambiente e produtividade. Grupo de Estudos Logísticos da Universidade Federal de Santa Catarina, 2005.

RAVI, V; SHANKAR, R; TIWARI, M. K. Selection of a reverse logistics project for end-of-life computers: ANP and goal programming approach. International Journal of Production Research, v 26, Issue 17, p. 4849-4870, 2008.

RECELLULAR NEWS. Recellular prevented 612.000 pounds of hazardous waste in 2009. Disponível em: www.recellular.com. Acesso em 07.07.2010.

RUBIO, S; CHAMORRO, A; MIRANDA, F. J. Characteristics of the research on reverse logistics (1995-2005). International Journal of Production Research, v. 46, n. 4, p. 1099-1120, 2008.

SANTOPIETRO, G. Raising environmental consciousness versus creating economic incentives as alternative policies for environmental protection. Journal of Economic Issues, v. 29, n 2, p. 517-524, 1995.

SHIMP, T. A. Propaganda e promoção: aspectos complementares da comunicação integrada de marketing (5ª ed.). São Paulo: Bookman, 2002.

SCHULTZ, D. E; SCHULTZ, H. F. Transitioning marketing communication into the twenty-first century. Journal of Marketing Communications, v. 4, n. 1, p. 9-26, 1998.

SCHULTZ, D. E; SCHULTZ, H. F. IMC next generation. New York: McGraw-Hill, 2004.

SCHULTZ, D. E; WALTERS, J. Measuring brand communication ROI. New York: Association of National Advertisers, Inc., 1997.

SOUZA, M. T. S. de; SANTOS, C. C. dos; LIMA, M. do C. F. Um estudo sobre o impacto ambiental da inovação tecnológica no setor de telecomunicações. Universidade Positivo, 2007. Disponível em: http://pgamb.up.edu.br/arquivos/ engema/pdf/PAP0232.pdf. Acesso em 03.05.2010.

STOCK, J. R; MULKI, J. P. Product returns processing: an examination of practices of manufacturers, wholesalers, distributors and retailers. Journal of Business Logistics, v. 30, n. 1, p. 33-62, 2009. 